\title{
Methadone in the Management of Intractable Neuropathic Noncancer Pain
}

\author{
D. E. Moulin, D. Palma, C. Watling, V. Schulz
}

\begin{abstract}
Objective: To evaluate the role of methadone in the management of intractable neuropathic noncancer pain. Methods: A case series of 50 consecutive noncancer pain patients who were seen at a tertiary care centre and treated with oral methadone for a variety of intractable neuropathic pain states. Results: The mean age was 52.7 years and the mean duration of follow-up was 13.9 months. Post-discectomy nerve root fibrosis, complex regional pain syndrome, peripheral neuropathy and central spinal cord pain syndromes were the most common diagnoses. Over $90 \%$ had been treated with one or more tricyclic antidepressants and anticonvulsants and a similar number had received other adjuvant analgesics. All patients had failed treatment with one or more conventional opioid analgesics (mean 2.8) at a mean maximal morphine dose of $384 \mathrm{mg}$ (or equivalents) per day. Twelve patients had failed spinal cord stimulation. Nineteen patients $(38 \%)$ did not tolerate initial methadone titration or thought their pain was worse on methadone. Five patients $(10 \%)$ declared initial benefit but required repetitive dose escalation and eventually became non-responders. Twenty-six patients (52\%) reported mild (4), moderate (15), marked (6) or complete (1) pain relief and continued on methadone at a mean maintenance dose of $159.8 \mathrm{mg}$ /day for a mean duration of 21.3 months. Fourteen patients (28\%) reported improved function on methadone relative to previous treatments. Conclusions: Methadone appears to have unique properties including N-methyl-D-aspartate antagonist activity that may make it especially useful in the management of intractable neuropathic pain. This observation needs to be tested in randomized, controlled trials.
\end{abstract}

RÉSUMÉ: La méthadone dans la prise en charge de la douleur névropathique rebelle non cancéreuse. Objectif: Évaluer le rôle de la méthadone dans le traitement de la douleur névropathique rebelle d'origine non cancéreuse. Méthodes: Nous décrivons un groupe de 50 patients consécutifs référés à un centre de soins tertiaires et traités avec de la méthadone par voie orale pour des douleurs névropathiques rebelles non cancéreuses. Résultats: L'âge moyen des patients était de 52,7 ans et la durée moyenne du suivi était de 13,9 mois. Les diagnostics les plus fréquents étaient une fibrose radiculaire postdiscectomie, un syndrome de douleur régionale complexe, une neuropathie périphérique et un syndrome de douleur centrale suite à une lésion de la moelle épinière. Plus de $90 \%$ des patients avaient reçu un ou plusieurs antidépresseurs tricycliques et des anticonvulsivants, et autant de patients avaient reçu d'autres adjuvants des analgésiques. Tous les patients n'avaient pas répondu aux analgésiques opioïdes conventionnels (moyenne de 2,8) à une dose moyenne maximale de morphine de $384 \mathrm{mg}$ par jour ou l'équivalent. Chez douze patients, la stimulation spinale avait été inefficace. Dixneuf patients (38\%) n'ont pas toléré la dose initiale de méthadone ou ont eu l'impression que leur douleur était pire sous méthadone. Cinq patients (10\%) ont éprouvé un bénéfice au début du traitement, mais ont eu besoin de doses de plus en plus élevées et sont éventuellement devenus des non-répondeurs. Vingt-six patients (52\%) ont rapporté un soulagement léger (4), modéré (15), important (6) ou complet (1) de la douleur et ont continué le traitement à une dose moyenne de maintien de 159,8 mg/jour, pour une durée moyenne de 21,3 mois. Quatorze patients (28\%) ont rapporté une amélioration de leur état fonctionnel sous méthadone par rapport aux traitements antérieurs. Conclusions: La méthadone semble posséder des propriétés uniques dont une activité antagoniste du N-méthyl-D-aspartate qui peut s'avérer particulièrement utile dans le traitement de la douleur névropathique rebelle. Cette observation doit être validée par des essais cliniques contrôlés et randomisés.

Can. J. Neurol. Sci. 2005; 32: 340-343

Chronic neuropathic pain, resulting from injury to the central or peripheral nervous system, is a serious health problem. Although precise estimates of the prevalence of neuropathic pain are not available, some epidemiological data are available from the United States-more than three million people suffer from painful diabetic neuropathy ${ }^{1}$ and as many as one million from post-herpetic neuralgia. ${ }^{2}$ Clinical management remains challenging despite advances in the molecular biology and pathophysiology of neuropathic pain. ${ }^{3}$ Anticonvulsant and antidepressant treatments provide effective analgesia in less than $50 \%$ of patients ${ }^{4}$ and there is lingering reluctance to use opioid analgesics because of fears of tolerance, addiction and limiting side effects ${ }^{5}$ despite well-designed randomized controlled trials showing evidence of efficacy. ${ }^{6-11}$
Methadone is an older opioid analgesic that is structurally unrelated to any of the opium-derived alkaloids. It is a racemic mixture of S- and R-methadone that has been used for over 60 years as a potent analgesic and as maintenance therapy for opioid addiction. ${ }^{12}$ Methadone has several properties that make it

From the Departments of Clinical Neurological Sciences (DEM, DP, CW) and Anesthesia and Perioperative Medicine (VS), Faculty of Medicine, University of Western Ontario, London, Ontario, Canada

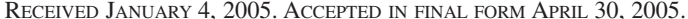
Reprint requests to: Dwight E. Moulin, London Regional Cancer Centre, 790 Commissioners Rd. E., London, Ontario, N6A 4L6, Canada 
attractive as an analgesic and more specifically as an analgesic in the management of chronic neuropathic pain. Methadone displays excellent oral bioavailability, a rapid onset of action, a long half-life, lack of active metabolites and incomplete crosstolerance with other opioids. ${ }^{13}$ In addition, the d-isomer (Smethadone) prevents mono amine reuptake in a manner similar to tricyclic antidepressants and has N-methyl-D-aspartate antagonist activity ${ }^{14,15}$ - properties that suggest specificity in the management of neuropathic pain. Given these attractive features, we evaluated methadone in the management of intractable neuropathic noncancer pain.

\section{Methods}

We analyzed the clinical charts of 50 consecutive patients who were treated with oral methadone (generic elixir) for intractable neuropathic pain in the Neuro Pain Clinic of London Health Sciences Centre, London, Ontario. Intractability was defined as failure to respond to standard adjuvant analgesics and at least one conventional controlled-release opioid analgesic. All patients reported moderate (16) to severe (34) pain at the time of the methadone trial. All prescriptions for oral methadone were initially filled in the hospital pharmacy which allowed us to track every patient treated in this manner. Opioid switching to methadone was accomplished according to the guidelines established by Mercandente et al. ${ }^{16}$ in the cancer pain population. The target dose of methadone was based on a scale of prior morphine equivalents according to low $(<90 \mathrm{mg}$ ), medium (90$300 \mathrm{mg}$ ) and high dose morphine $(>300 \mathrm{mg}$ ) per day. An oral morphine to methadone conversion ratio of four was used for low dose, eight for medium dose and 12 for high dose morphine with substitution of one-third of the target dose for the first five to seven days, two-thirds for the next five to seven days and then the full target dose if tolerated. The prior opioid was decremented in inverse fashion by dropping the dose by a third every five to seven days. Methadone was always prescribed every eight hours as most patients obtain adequate analgesia using this interval. ${ }^{17}$ Patients were seen initially in the Neuro

\section{Table 1: Patient Characteristics}

$\begin{array}{ll}\mathrm{N} & 50 \\ \text { Age }(\text { mean } \pm \mathrm{SE}) & 52.7 \pm 2 \\ \text { Male / Female } & 28 / 22 \\ \text { Diagnoses } & \end{array}$

$\begin{array}{ll}\text { Failed back syndrome with nerve root fibrosis } & 12 \\ \text { Complex regional pain syndrome (type 1) } & 9 \\ \text { Central pain syndrome } & 7 \\ \text { Peripheral neuropathies } & 6 \\ \text { Post-surgical pain syndrome } & 5 \\ \text { Post-herpetic neuralgia } & 3 \\ \text { Cauda equina syndrome } & 3 \\ \text { Miscellaneous } & 5\end{array}$

\section{Table 2: Failed Treatments for Neuropathic Pain}

\begin{tabular}{ll}
\hline & $\mathrm{N}(\%)$ \\
Conventional opioid analgesics & $50(100)$ \\
Anticonvulsants & $46(92)$ \\
Tricyclic antidepressants & $46(92)$ \\
Other adjuvant analgesics & $44(88)$ \\
Transcutaneous electrical nerve stimulation & $20(40)$ \\
Spinal cord stimulation & $12(24)$ \\
Epidural steroids & $6(12)$
\end{tabular}

Pain Clinic at least monthly until they reached a stable dose of methadone (or failed a methadone trial) and were then followed monthly by the referring physician and every three to six months in the Neuro Pain Clinic. Patients were considered to have reached a stable dose of methadone when they reported adequate pain control with an acceptable side effect profile for at least one month. At each follow-up visit, standard guidelines for the opioid management of chronic pain were observed ${ }^{18}$ including documentation of the five A's - analgesic dosing, analgesia (none, mild, moderate, marked or complete pain relief), adverse effects, activity level and aberrant drug-related behaviour. Given that these patients had already failed exhaustive pharmacologic interventions, we regarded analgesic response to methadone as the primary outcome measure and duration of methadone treatment as the secondary outcome measure. Data are presented as summary statistics (means \pm standard error) as appropriate.

The manuscript, including the retrospective chart review approach, was reviewed by the University of Western Ontario Health Sciences Research Ethics Board and they concluded that the protocol was conducted in an ethical manner.

\section{Results}

\section{Study Population}

The clinical characteristics of the study population are illustrated in Table 1. All 50 patients, but one, described one or more of the classical features of neuropathic pain including burning, lancinating pain and touch-evoked pain or allodynia. The most common intractable neuropathic pain syndrome observed was post-discectomy nerve root fibrosis which was supported by imaging evidence of epidural scarring in all 12 cases. All of these patients reported a minor component of aching low back pain and a major component of neuropathic pain down the leg - usually in L5 or S1 distribution. All of the central pain syndromes were due to spinal cord injury.

Table 2 describes failed treatments for neuropathic pain. Almost all patients failed one or more trials of anticonvulsants, tricyclic antidepressants and other adjuvant analgesics including clonidine, mexilitene and clonazepam. Over half failed treatment with physical medicine approaches and anesthetic techniques. Every patient received a trial of one or more conventional controlled-release opioid analgesics including morphine, hydromorphone, oxycodone and transdermal fentanyl. In fact, 
the majority of patients received sequential trials of two or three conventional opioids (mean 2.8 \pm 1.2 ). The mean maximal opioid dose prior to switching to methadone was $384 \pm 64.6 \mathrm{mg} /$ day expressed as oral morphine equivalents. ${ }^{19}$ Twenty-seven patients (54\%) failed conventional opioids because of intolerable side effects and $23(46 \%)$ failed because of lack of a significant analgesic response to incremental dosing.

\section{Methadone Treatment}

Table 3 illustrates the clinical characteristics of methadone treatment for neuropathic pain. Twenty-six patients declared an adequate analgesic response and have continued on methadone for a mean duration of 21.3 months. Three of seven patients with central neuropathic pain due to spinal cord injury are in this group. Eleven of the 26 responders have had persistent mild side effects including drowsiness in seven, constipation in one and nausea in one which were considered tolerable and they elected to continue on methadone. Twenty-four patients failed a trial of methadone over a mean treatment period of 5.4 months even though nine of them reported mild, moderate or marked pain relief. Nineteen of these patients developed intolerable adverse effects and five failed to respond to incremental dosing and eventually became non-responsive. The primary intolerable side effects following conversion to methadone were nausea and vomiting in 11, drowsiness in six and constipation in two. There were no cases of respiratory depression. Fourteen of 26 responders $(53.8 \%)$ but only two of 24 non-responders $(8.3 \%)$ reported an improvement in function.

\section{Discussion}

Although there are inherent limitations in any case series, the strengths of this clinical trial are that it involves 50 consecutive patients who have been treated in a uniform manner and carefully followed according to standardized guidelines for opioid management of chronic pain. ${ }^{18}$ Previous reports involving chronic neuropathic noncancer pain have been largely restricted to chart reviews with single or multiple case reports. ${ }^{20-24} \mathrm{~A}$ recent prospective trial of oral methadone showed benefit in 18 patients with predominantly cancer-related neuropathic pain, ${ }^{25}$ but this was an open-label study that was significantly underpowered.

The response to oral methadone in our study was dramatic in that $52 \%$ of patients declared benefit and have continued on methadone for almost two years despite failing all other pharmacologic approaches. Even more striking is the observation that half the patients declared a beneficial response to methadone even though they failed very aggressive trials of conventional opioids at a mean maximal morphine dose of 384 $\mathrm{mg} /$ day. Previous maximal opioid exposure did not predict the response to methadone (responders $412 \mathrm{mg}$ /day versus nonresponders $354 \mathrm{mg} / \mathrm{day}$ ). The response to methadone parallels the reported experience in clinical surveys of the long-term use of opioids in chronic noncancer pain ${ }^{26}$ indicating that pharmacological tolerance is not a significant determinant of opioid dosing requirements. Methadone responders reached their maximal dose at a mean of 8.3 months and have continued treatment for a mean of 21.3 months (Table 3 ).

Methadone may be a first or second line opioid analgesic in the management of neuropathic pain. It is now available in pill
Table 3: Clinical Characteristics of Methadone Treatment $(\mathbf{N}=\mathbf{5 0})$

\begin{tabular}{ll}
\hline & Mean $\pm \mathrm{SE}$ \\
Initial target dose (mg/day) & $50 \pm 4.0$ \\
Maintenance (maximal) dose (mg/day) & \\
All patients & $121.4 \pm 24.1$ \\
Responders $(\mathrm{N}=26)$ & $159.8 \pm 28.9$ \\
Non-responders $(\mathrm{N}=24)$ & $78.0 \pm 15.4$ \\
Time to maximal dose (months) & \\
All patients & $6.2 \pm 1.5$ \\
Responders $(\mathrm{N}=26)$ & $8.3 \pm 1.6$ \\
Non-responders $(\mathrm{N}=24)$ & $3.7 \pm 1.2$ \\
Duration of treatment $(\mathbf{m o n t h s})$ & \\
All patients & $13.9 \pm 2.6$ \\
Responders $(\mathrm{N}=26)$ & $21.3 \pm 2.9$ \\
Non-responders $(\mathrm{N}=24)$ & $5.5 \pm 1.7$
\end{tabular}

Pain relief - Responders $(\mathrm{N}=26)$

Mild

4

Moderate

15

Marked

6

Complete

1

form (Metadol, PharmaScience, Montreal, Quebec) although generic methadone elixir is considerably less expensive than methadone tablets or other opioids at equianalgesic doses. ${ }^{16}$ The unique properties of the d-isomer as an enhancer of monoamine activity and as an N-methyl-D-aspartate (NMDA) antagonist may in part explain the efficacy when conventional opioid analgesics have failed. In addition, methadone has greater affinity for the delta opioid receptor than morphine ${ }^{13}$ and all of these properties might be responsible for the phenomenon of incomplete cross-tolerance when patients are switched from conventional opioids such as morphine to methadone. Opioid switching is a recognized valuable technique in the management of intractable cancer pain. ${ }^{16}$

Enthusiasm for the use of methadone as an analgesic agent must be tempered by several factors. The longstanding use of methadone as maintenance therapy for opioid addiction has stigmatized methadone as an analgesic and this is problematic for some patients and physicians. Methadone usually has an elimination half-life of $30-60$ hours $^{13}$ which makes dose titration labour intensive. However, because of significant interindividual variation, elimination half-lives in the range of 4.2-130 hours have been reported. ${ }^{27}$ Opioid switching to methadone must be accomplished with great care because the equianalgesic dose can vary tremendously based on previous opioid exposure, the unique physiochemical properties of methadone and variable pharmacogenomics. ${ }^{28,29}$ All of these 
factors may explain the clinical observation that switching to methadone in patients who have been receiving high doses of conventional opioids can provide better pain relief at doses of methadone that are ten percent or less of a calculated equianalgesic dose based on single dose studies. ${ }^{30}$ There are also recent reports of polymorphic ventricular tachycardia (torsade de pointes) in patients on high dose methadone (mean dose 397 $\mathrm{mg} /$ day) $)^{31}$ and this has lead to a recent recommendation to do screening electrocardiograms to monitor the QT interval in atrisk patients. ${ }^{32}$

Given methadone's potential advantages as an analgesic agent but also potential difficulties, who should prescribe methadone for chronic pain? In Canada, methadone use for pain or opioid addiction requires special physician authorization from the Federal Bureau of Drug Surveillance which then makes a recommendation for exemption to prescribe methadone to the provincial medical licensing authority. Detailed guidelines for the use of methadone for chronic pain are available from the College of Physicians and Surgeons of Ontario ${ }^{33}$ and from a recent review article extracted from the College of Physicians and Surgeons of Nova Scotia. ${ }^{34}$ Any physician prescribing methadone for chronic pain would need to be very familiar with these guidelines. Alternatively, a patient being considered for methadone treatment for chronic pain, and specifically for neuropathic pain, could be referred to a pain clinic with the expertise and authorization for its use. Beyond present guidelines, there is an urgent need for randomized controlled trials to further delineate the efficacy and safety of methadone in the management of malignant and nonmalignant neuropathic pain syndromes.

\section{REFERENCES}

1. Schmader KE. Epidemiology and impact on quality of life of postherpetic neuralgia and painful diabetic neuropathy. Clin $\mathrm{J}$ Pain 2002;18:350-354.

2. Bowsher D. The lifetime occurrence of herpes zoster and prevalence of postherpetic neuralgia: a retrospective survey in an elderly population. Eur J Pain 1999;3:335-342.

3. Bridges D, Thompson SWN, Rice ASC. Mechanisms in neuropathic pain. Br J Anesth 2001;87:12-26.

4. Sindrup HJ, Jensen TS. Efficacy of pharmacological treatments of neuropathic pain: An update and effect related to mechanism of drug action. Pain 1999;83:389-400.

5. Carver A, Foley K. Facts and an open mind should guide clinical practice. Curr Neurol Neurosci Rep 2001;1:97-98.

6. Watson CPN, Babul N. Efficacy of oxycodone in neuropathic pain: A randomized trial in postherpetic neuralgia. Neurology 1998;50:1837-1841.

7. Huse E, Larbig W, Flor H, et al. The effect of opioids on phantom limb pain and cortical reorganization. Pain 2001;90:47-55.

8. Raja SN, Haythornthwaite JA, Pappagallo M, et al. Opioids versus antidepressants in postherpetic neuralgia. Neurology 2002;59:1015-1021.

9. Gimbel JS, Richards P, Portenoy RK. Controlled-release oxycodone for pain in diabetic neuropathy. Neurology 2003;60:927-934.

10. Watson CPN, Moulin DE, Watt-Watson J, Gordon A, Eisenhoffer J. Controlled-release oxycodone relieves neuropathic pain: a randomized, controlled trial in painful diabetic neuropathy. Pain 2003;105:71-78.
11. Rowbotham MC, Twilling L, Davies PS, et al. Oral opioid therapy for chronic peripheral and central neuropathic pain. New Eng J Med 2003;348:1223-1232.

12. Joseph H, Stancliff S, Langrod J. Methadone maintenance treatment (MMT): A review of historical and clinical issues. Mt Sinai J Med 2000;67:347-364.

13. Fishman SM, Wilsey B, Mahajan G, et al. Methadone reincarnated: Novel clinical applications with related concerns. Am Acad Pain Med 2002;3:339-348.

14. Codd EE, Shank RP, Schupsky JJ, et al. Serotonin and norepinephrine uptake inhibiting activity of centrally acting analgesics: Structural determinants and role in antinociception. J Pharmacol Exp Ther 1995;274:1263-1270.

15. Davis AM, Inturrisi CE. d-Methadone blocks morphine tolerance and N-methyl-D-aspartate -induced hyperalgesia. J Pharmacol Exp Ther 1999;289:1048-1053.

16. Mercadante S, Casuccio A, Fulfaro F, et al. Switching from morphine to methadone to improve analgesia and tolerability in cancer patients: a prospective study. J Clin Oncology 2001:2898-2904.

17. Bruera E, Sweeney C. Methadone use in cancer patients with pain. J Palliative Med 2002;5:127-137.

18. Jovey RD, Ennis J, Gardner-Nix J, et al. Use of opioid analgesics for the treatment of chronic noncancer pain - A consensus statement and guidelines from the Canadian Pain Society, 2002. Pain Res Manage 2003;8:3A-14A.

19. Levy MH. Pharmacologic treatment of cancer pain. New Eng J Med 1996;335:1124-1132

20. Hampf GBC, Kalso EA. Chronic use of opioids in intractable facial pain. Acta Odontol Scand 1991;49:215-218.

21. Altier N, Dion D, Boulanger A, et al. Successful use of methadone in the treatment of chronic neuropathic pain arising from burn injuries: A case study. Burns 2001;27:771-775.

22. Bergmans L, Snijdelaar DG, Katz J, et al. Methadone for Phantom Limb Pain. Clin J Pain 2002;18:203-205.

23. Gardner-Nix JS. Oral methadone for managing chronic nonmalignant pain. J Pain Symptom Manage 1996;11:321-328.

24. Mironer YE, Haasis JC III, Chapple IT, et al. Successful use of methadone in neuropathic pain: A multicentre study by the National Forum of Independent Pain Clinicians. Pain Digest 1999;9:191-193.

25. Gagnon B, Almahrezi MB, Schreier G. Methadone in the treatment of neuropathic pain. Pain Res Manage 2003;8:149-154.

26. Zenz M, Strumpf M, Tryba M. Long-term oral opioid therapy in patients with chronic nonmalignant pain. J Pain Symptom Manage 1992;7:69-77.

27. Davis M, Walsh D. Methadone for the relief of cancer pain: a review of pharmacokinetics, pharmacodynamics, drug interactions and protocols of administration. Support Care Cancer 2001;9:73-83.

28. Moulin DE. Use of methadone for neuropathic pain. Pain Res Manage 2003;8:131-132.

29. Pasternak GW. Incomplete cross-tolerance and multiple mu opioid peptide receptors. Trends Pharmacol Sci 2001;22:67-70.

30. Ripamonti C, Groff L, Brunelli C, et al. Switching from morphine to oral methadone in treating cancer pain: What is the equianalgesic dose ratio? Clin Oncol 1998;16:3216-3221.

31. Krantz MJ, Lewkowiez L, Hays H, et al. Torsade de pointes associated with very high dose methadone. Ann Intern Med 2002;137:142.

32. Wood AJJ. Drug-induced prolongation of the QT interval. N Eng J Med 2004;350:1013-1022.

33. Cunningham G, Bodley S, Chaiet A, et al. Methadone for pain guidelines. College of Physicians and Surgeons of Ontario, November 2004 (www.cpso.on.ca).

34. Lynch ME. A review of the use of methadone for treatment of chronic non-cancer pain. Pain Res and Manage (in press). 